\title{
METODOLOGIAS PARA DETERMINAR QUALIDADE FISIOLÓGICA EM SEMENTES DE FEIJÃO ENFATIZANDO O TESTE DE TETRAZÓLIO
}

\author{
Débora Perdigão Tejo', Carlos Henrique dos Santos Fernandes², Marizangela Rizzatti Ávila \\ ${ }^{1}$ Engenheira Agronoma, mestranda em Agronomia, Universidade Estadual de Ponta Grossa (UEPG); \\ ${ }^{2}$ Engenheiro Agronomo, mestrandoem Agronomia, Universidade Estadual de Londrina (UEL); \\ ${ }^{3}$ Engenheira Agronoma, pesquisadora da Área de Produção Vegetal, Instituto Agronomico do Paraná (IAPAR).
}

\begin{abstract}
RESUMO: A cultura do feijão (Phaseolus vulgaris L.) tem destaca no setor do agronegócio nacional por se tratar de uma espécie amplamente cultivada em todo o país. Para se obter sucesso em relação a sua produção e produtividade é indispensável o emprego de sementes com bons índices de qualidade fisiológica, visto que a propagação do feijoeiro é via sementes. Qualidade fisiológica abrange conceitos relacionados aos atributos de viabilidade e vigor, sendo estes comumente determinados por metodologias que avaliam o desempenho de amostras de sementes em condições controladas, dentre estas metodologias encontra-se o teste de germinação (primeira contagem para obter parâmetros sobre o vigor, e contagem final para viabilidade); comprimento de plântulas, matéria seca, envelhecimento acelerado, condutividade elétrica fornecem parâmetros a respeito do atributo vigor; o teste de tetrazólio, por sua, vez destaca-se por ser uma metodologia que fornece resultados de maneira rápida (aproximadamente 24 horas), precisa e eficaz, além de possibilitar avaliações tanto sobre o aspecto de viabilidade como de vigor, podendo classificar as amostras em sete diferentes classes, também permite identificações de possíveis danos que prejudicariam a qualidade fisiológica das sementes.
\end{abstract}

Palavras-chave: Viabilidade, vigor, feijoeiro.

\section{METHODOLOGIES TO DETERMINE PHYSIOLOGICAL QUALITY IN BEAN SEEDS EMPHASIZING THE TETRAZOLOUS TEST}

ABSTRACT: The bean crop (Phaseolus vulgaris L.) has been outstanding in the national agribusiness sector because it is a widely cultivated species throughout the country. In order to obtain success in relation to its production and productivity it is indispensable to use seeds with good indexes of physiological quality, since the propagation of the bean is via seeds. Physiological quality encompasses concepts related to the attributes of viability and vigor, and these are commonly determined by methodologies that evaluate the performance of seed samples under controlled 
conditions, among these methodologies is the germination test (first count to obtain parameters on vigor, and final count for viability); length of seedlings, dry matter, accelerated aging, electrical conductivity provide parameters regarding the vigor attribute; the tetrazolium test, in turn, stands out as a methodology that provides results in a fast (approximately 24 hours), accurate and efficient, as well as making possible evaluations on both the viability and the vigor aspects, being able to classify the samples in seven different classes, also allows identification of possible damages that would impair the physiological quality of the seeds.

Keywords: viability, vigor, common bean.

\section{INTRODUÇÃO}

A cultura do feijoeiro comum (Phaseolus vulgaris L.) tem sua propagação executada via sementes, assim como a maioria absoluta das demais culturas de interesse econômico, sendo assim é crucial o emprego de sementes de alta qualidade a fim de se obter estabelecimento de estande adequado e uma alta produtividade (KRZYZANOWSKI, 2009). Segundo Delouche (2005) é indispensável sementes que disponham de alta qualidade em produções agrícolas em que as mesmas são um insumo básico.

A qualidade de sementes abrange aspectos relacionados com sua genética, fisiologia e sanidade, atributos estes que irão refletir na competência de a semente originar uma plântula normal, com estabelecimento de estande uniforme, ausência de patologias que podem ser transmitidas via semente, alta viabilidade e vigor, e com alta capacidade produtiva (POPINIGIS, 1985; MARCOS FILHO, 2015).

Todos os atributos que constituem a qualidade de sementes possuem importância similar, entretanto, por abordar a degeneração de sementes após o processo de maturação, o atributo fisiológico se destaca nos estudos científicos desenvolvidos com sementes (ABDUL-BAKI; ANDERSON, 1970; VIEIRA; RAVA, 2000).

$\mathrm{O}$ atributo fisiológico, é denominado qualidade fisiológica, e se defini como a capacidade da semente executar suas funções vitais por meio do processo de germinação, vigor e de sua longevidade. Sendo assim a qualidade fisiológica abrange os conceitos de viabilidade e vigor das sementes (POPINIGIS, 1985; KRZYZANOWSKY; FRANÇA NETO, 1999; FRANCO; MAGALHAES JUNIOR, 2011). Neste sentido o objetivo do presente estudo foi conceituar os parâmetros de viabilidade e vigor, abordar metodologias aplicadas rotineiramente em laboratórios de análises de sementes com intuito de atestar a qualidade fisiológica de sementes da cultura do feijão, com destaque para o teste de tetrazólio. 


\section{MATERIAL E MÉTODOS}

O presente trabalho trata-se de uma revisão de literatura, elaborado em cima de consultas em livros, dissertações, artigos publicados em revistas com teor científicos e boletins técnicos emitidos por Instituições renomadas como FAO, Conab, Embrapa, entre outros.

\section{CONCEITO DE VIABILIDADE E VIGOR}

Viabilidade consiste na determinação se a semente está viva ou não, comumente expressada pelo poder germinativo da mesma, vale ressaltar que o teste de germinação possui alta padronização e pode ser facilmente reproduzido (PERRY, 1981; CARVALHO; NAKAGAWA, 2000). Já o vigor diz respeito a capacidade da semente expressar seu potencial germinativo em condições de algum estresse, ou seja, quando as condições ideias para o desenvolvimento da semente em plântula não estão reunidas (FRANÇA NETO; KRZYZANOWSKI; HENNING, 2011).

O INTERNATIONAL SEED TESTING ASSOCIATION - ISTA (1981) definiu o vigor como sendo do desempenho de uma determinada amostra de sementes no ato da germinação ou emergência das plântulas. A ASSOCIATION OF OFFICIAL SEED ANALYSTS - AOSA (1983) determinou que o vigor se refere a capacidade de emergência de plântulas normais de modo rápido e uniforme em condições climaticas variadas.

Para sementes de feijão os testes laboratoriais que expressam o vigor são primeira contagem de germinação, envelhecimento acelerado, comprimento de plântula, material seca, condutividade elétrica e tetrazólio (KRZYZANOWSKI; FRANÇA-NETO; HENNING, 1991; VIEIRA; CARVALHO, 1994).

\section{TESTE DE GERMINAÇÃO EM SEMETES DE FEIJÃO}

O teste de germinação mostra-se eficaz na determinação do potencial germinativo de amostras de sementes quando as condições para seu desenvolvimento são ótimas, ou seja, ideais de temperatura e umidade. Em laboratório se caracteriza pela emergência das estruturas que constituem o eixo embrionário, revelando deste modo a competência das sementes em produzir uma 
plântula normal em situações favoráveis de campo (NONOGAKI; BASSEL; BEWLEY, 2010; MARCOS FILHO, 2015).

Tal teste é conduzido em ambiente artificial e controlado, que deste modo irão proporcionar condições ideias exigidas pela espécie para ocorrer a germinação, devido pode-se verificar em determinadas situações divergência de resultados entre os resultados obtidos em laboratório e os observados posteriormente a campo. A coincidência entre os resultados do teste de germinação e a emergência o campo só ocorrer em quando o ambiente do campo também oferecer todas as condições favoráveis para o desenvolvimento inicial da cultura, vale ressaltar que os resultados do teste de germinação são expressos por meio da porcentagem de plântulas consideradas normais em um determinado período (BRAZ; ROSSETTO, 2009).

Para a cultura do feijoeiro comum, a metodologia de aplicação do teste de germinação é descrita nas Regras para Análise de sementes - RAS (BRASIL, 2009), onde conta que não é necessário preparo prévio para quebra de dormência, e pode ser aplicado em rolo de papel ou entre areia. Quando executado em rolos de papel, ou seja, em substrato de papel, as sementes são organizadas sobre duas folhas de papel e encobertas por uma terceira folha, sendo os tipos de papeis mais empregados mata-borrão, toalha e o filtro.

De modo prévio à disposição das sementes sobre as folhas de papel, as mesmas devem ser umedecidas com água destilada, o volume (mililitro) de água a ser utilizada segue o cálculo que considera o peso (grama) do substrato e o multiplica por 2,5. Após isso o substrato papel está apto a receber as sementes para germinação, sendo estas organizadas normalmente com auxílio de tabuas de germinação, cada rolo de papel deve conter cinquenta sementes, sendo necessário realizar quatro repetições para cada amostra avaliada (BRASIL, 2009).

Os rolos de papel são conduzidos diretamente sobre as bandejas do germinador (Figura 1), que deve estar devidamente regulado oferecendo uma temperatura constante de $25^{\circ} \mathrm{C}$, ou alternando em 20 $\mathrm{C}$ (por um período de 16 horas - noturno) e $30^{\circ} \mathrm{C}$ (por um período de 8 horas - diurno). A avaliação é realizada nove dias após a instalação e as plântulas são classificadas em normais (plântulas intactas ou com pequenos defeitos ou com infecções consideradas segundarias); anormais (plântulas danificadas, deformadas ou deterioradas) e não germinadas (duras ou mortas) (BRASIL, 2009). 


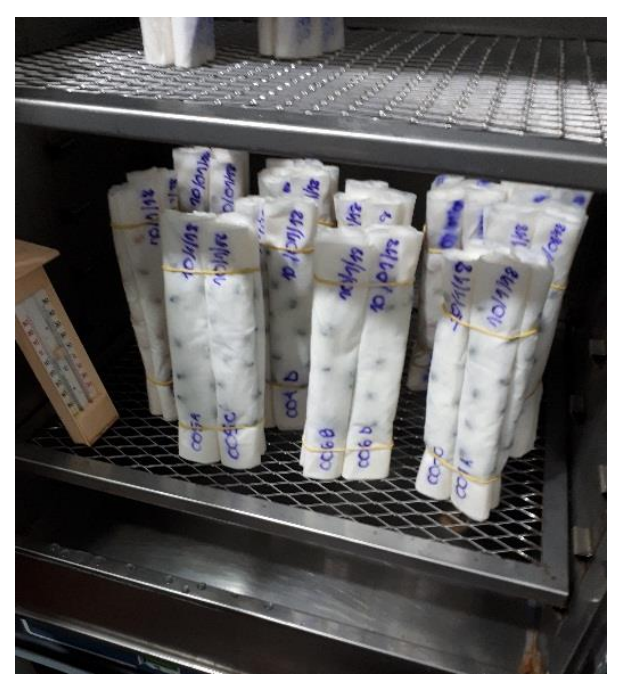

Figura 1 - Rolos de germinação com sementes de feijão condicionadas no interior de germinadores. Fonte: Tejo (2018).

A execução do teste em substrato areia (entre areia) é uma alternativa para confirmação dos resultados obtidos nos testes em rolos de papel, principalmente quando as plântulas demonstraram sintomas de fitopatologias ou fitotoxidades. Para a espécie Phaseolus vulgaris a areia deve ser umedecida com $60 \%$ de sua capacidade de retenção, e em seguidas as sementes são dispostas de forma similar aos rolos de papel e encobertas por areia solta (em torno de 1 centímetro). As avalições são executadas nove dias após a instalação e seguem os padrões determinados para testes conduzidos em rolos de papel (BRASIL, 2009).

O teste de germinação trata-se de uma metodologia que pode ser conduzido com duas etapas de avaliação, ou seja, duas contagens de plântulas; na primeira contagem os rolos são abertos e as plântulas que estiverem normais são contadas, retiradas dos rolos e descartadas, em seguida os rolos são novamente fechados e conduzidos novamente ao germinador onde estavam previamente. Para aplicação do método de germinação em areia normalmente a primeira contagem de germinação não é realizada (NAKAGAWA, 1999).

No ato desta avaliação conclui-se que as plântulas que se mostraram-se normais germinaram primeiro e logo tratam-se de sementes com mais vigor, sendo assim os lotes que apresentarem maiores porcentagens de plântulas normais na avaliação da primeira contagem de germinação, são os mais vigorosos. Trata-se da única metodologia de avaliação de vigor reconhecida pelas regras de análise de sementes reconhecida pelo Ministério da Agricultura do Brasil (BRASIL, 2009). 


\section{TESTE DE COMPRIMENTO DE PLÂNTULAS NO FEIJOEIRO}

No teste de comprimento de plântula é verificado a média do comprimento de plântulas normais ou de suas estruturas separadamente, como raiz primaria (radícula), hipocótilo, epicótilo e plúmula; ao término das avaliações é considerada a amostra com maior vigor a que dispor de maior média no comprimento de plântulas (NAKAGAWA, 1999).

A condução da metodologia se assemelha a de germinação, com a diferença de que neste caso a quantidade de sementes empregada em cada repetição é de vinte sementes, devidamente organizadas de modo intercalado, em duas linhas longitudinais, as sementes devem ser posicionadas de modo intercalado a fim de excluir possíveis interferências no crescimento do sistema aéreo e radicular de cada semente (Figura 2). Vale ressaltar que a região do sistema radicular de cada semente deve ser posicionada para baixo, com intuito de propiciar um desenvolvimento retilíneo, no caso da cultura do feijão emprega-se a micrópila para o interior do papel (AOSA, 2009).

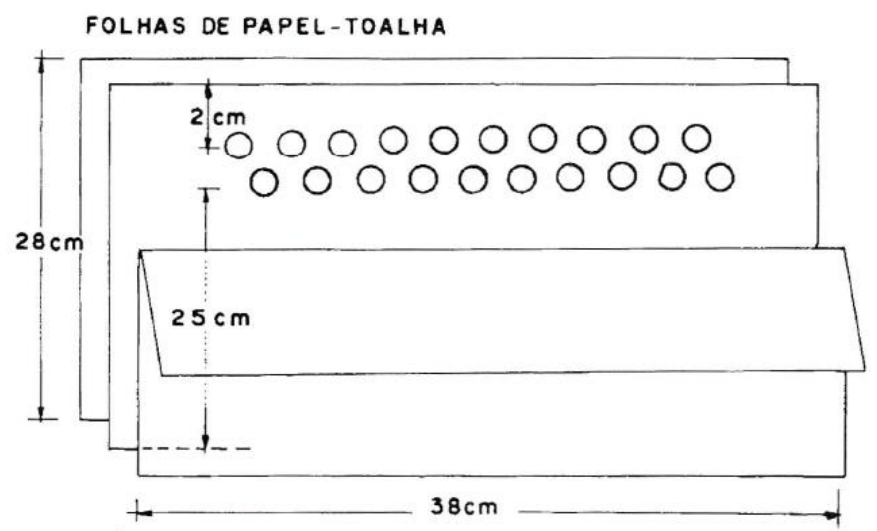

Figura 2 - Disposição das sementes sobre as folhas de papel de germinação, para condução do teste de comprimento de plântula. Fonte: Krzyzanowski; França-Neto; Henning (1991).

Após a disposição das sementes os rolos são fechados (Figura 3), as repetições agrupadas e conduzidas ao interior de sacos plásticos escuros e posteriormente acondicionadas em germinadores regulados com temperatura similar à adotada no teste de germinação. A utilização de sacos plásticos é crucial para manter a umidade ideal no substrato papel (MARCOS FILHO; CICERO; SILVA, 1987). 


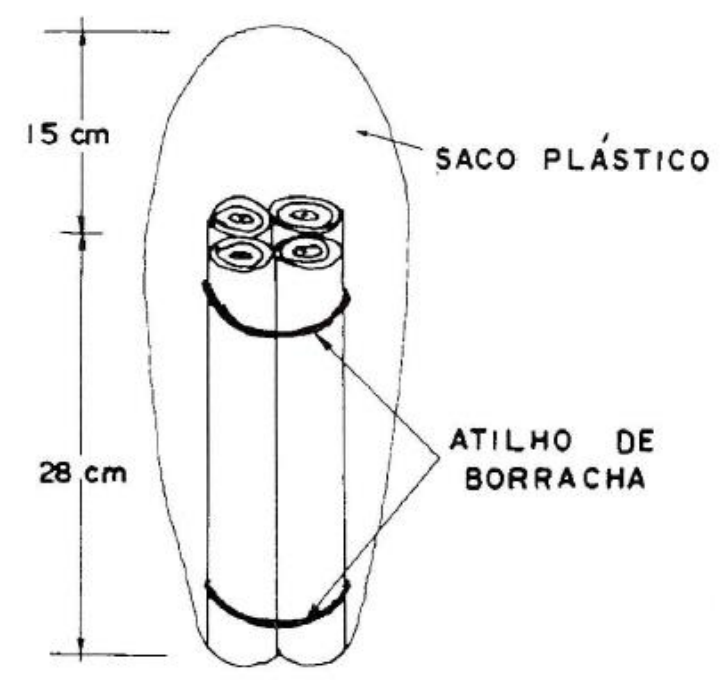

Figura 3 - Rolos de germinação acondicionados no interior de sacos plásticos. Fonte: Krzyzanowski; França-Neto; Henning (1991).

As avaliações são realizadas, para cultura do feijoeiro comum, sete dias após instalação do teste, sendo efetuada com auxílio de uma régua milimetrada que permite aferir o comprimento das devidas estruturas das plântulas. É realizada a média dos valores de comprimento de plântulas aferidos em cada amostra, e se determina a amostra com mais vigor aquela que dispor de maior média no teste (ISTA, 2008; AOSA, 2009).

Determinação de matéria seca pode ser realizada na sequência da avaliação do teste de comprimento de plântula, e possibilita a determinação da média da matéria seca das plântulas. As plântulas são submetidas a secção que pode ser executada por meio de bisturis ou lâminas, para deste modo haver a retirada dos cotilédones da plântula de feijão, pode também realizar a separação das estruturas áreas e radiculares; posteriormente são conduzidas ao interior de compartimentos previamente tarados como sacos de papel ou recipientes de alumínio, vale ressaltar que é adotado um recipiente para cada repetição (NAKAGAWA, 1994).

Após preparo das amostras nos devidos recipientes, estes são conduzidos ao interior de estufas termoelétricas reguladas a uma temperatura constante de $105^{\circ} \mathrm{C}$ por um período de 24 horas, para proporcionar a secagem das plântulas. Suprido este período, os compartimentos onde as amostras estão devidamente acondicionadas, são colocados em dessecadores para desta forma promover o resfriamento do material (NAKAGAWA, 1994). 
O material seco e resfriado deve ser pesado em balanças, estas deve apresentar uma precisão de 0,001 grama (g) ou 0,0001 grama (g), obtendo deste modo peso seco das plântulas normais, o procedimento é realizado com todas as plântulas normais de todas as repetições; é desempenhada uma média com os valores obtidos em todas plântulas dentro de cada repetições e subsequentemente se executa novamente uma média entre as repetições para cada amostra submetida a esta metodologia. Ao término das avaliações são consideradas as amostras com maior vigor aquelas que dispuseram de medias mais elevadas de matéria seca (NAKAGAWA, 1994).

\section{TESTE DE ENVELHECIMENTE ACELERADO EM SEMENTES DE FEIJÃO}

A metodologia de envelhecimento acelerado avalia o desenvolvimento de sementes em condições de temperatura e umidade elevadas, com intuito de avaliar o comportamento e o potencial fisiológico das sementes após um período relativo de armazenamento. Avalia os níveis de deterioração, visto que, este é acrescido em condições extremas de temperatura e umidade (TEKRONY, 1995; DELOUCHE, 1965).

Para a cultura do feijoeiro comum utiliza-se o método do gerbox, sendo este considerado um método padronizado e de precisão; as caixas plásticas de gerbox (Figura 4) possuem dimensões de 11,0 x 11,0 x 3,0 cm, e devem dispor de uma bandeja caracterizada em forma de tela de arame ou cobre, onde são acondicionadas as sementes que permanecerão suspensas no interior do gerbox (MARCOS FILHO, 1999).

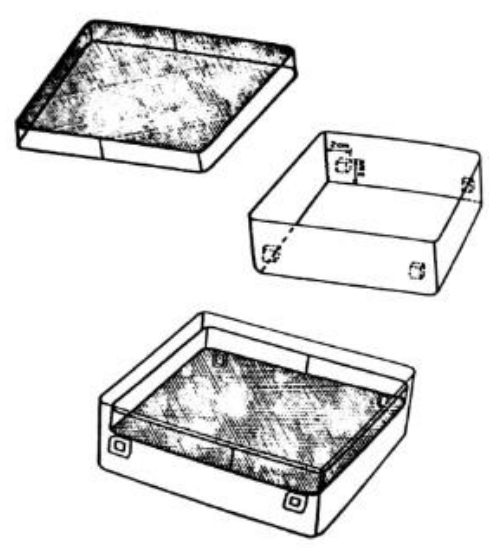

Figura 4 - Caixas de gerbox utilizadas no teste de envelhecimento acelerado. Fonte: Krzyzanowski; França-Neto; Henning (1991). 
A caixa de gerbox desempenha papel de câmara interna, sendo assim com intuito de propiciar $100 \%$ de umidade relativa em seu interior são adicionadas $40 \mathrm{ml}$ de água destilada no fundo da caixa, acima foi colocado a bandeja de tela de arame com as sementes, neste momento os procedimentos devem ser realizados com 0 máximo de cuidado afim de evitar o contato das sementes com a água (MARCOS FILHO, 1994).

Após o preparo das sementes nas caixas, estas são conduzidas para o interior de uma câmara de envelhecimento (Figura 5) que propicia uma temperatura constante de $42^{\circ} \mathrm{C}$ por um período de 72 horas, tais valores foram definidos por meio de trabalhos realizados por meio da comparação de resultados obtidos em trinta laboratórios que tinham como intuito de padronizar esta metodologia para a cultura do feijão (MARCOS FILHO, 1999).

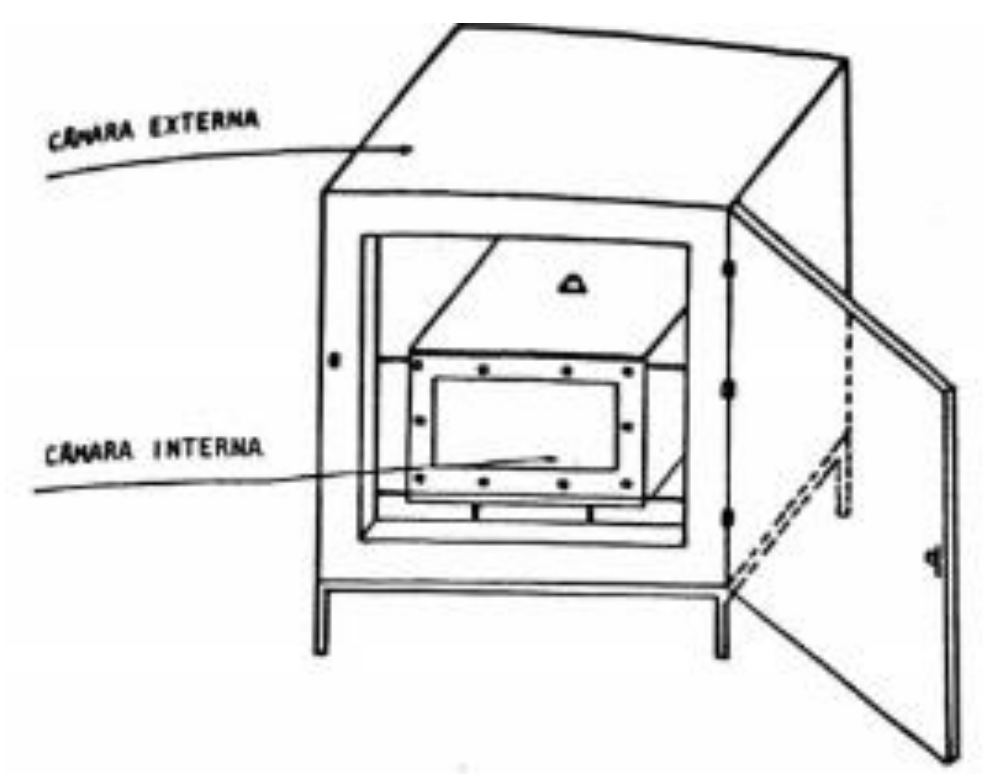

Figura 5 - Câmara de envelhecimento. Fonte: Krzyzanowski; França-Neto; Henning (1991).

Suprido o período de exposição das sementes na câmara de envelhecimento, deve-se conduzir o teste de germinação nas sementes que foram envelhecidas, a avaliação dos resultados do teste de germinação é devidamente executada quatro dias após a instalação da germinação e os parâmetros de avaliação são os mesmos que são considerados no teste de germinação previamente descrito (MARCOS FILHO; NOVEMBRE; CHAMMA, 2001).

Vale ressaltar que a quantidade de sementes utilizadas no teste de envelhecimento acelerado deve ser suficiente para instalação do teste de germinação 
com repetição de quatro rolos, ou seja, duzentas sementes; as sementes não devem se sobrepor na badeja da caixa de gerbox, devendo estar distribuídas uniformemente, pode-se fazer uso de mais de uma caixa de gerbox para cada amostra, sendo comumente empregadas duas caixas para cada amostra (MARCOS FILHO, 1994).

\section{TESTE DE CONDUTIVIDADE ELÉTRICA NO FEIJOEIRO}

O teste de condutividade elétrica verifica o vigor das sementes por meio da integridade de suas membranas. Inicialmente as sementes são submetidas ao procedimento de embebição, e neste momento se as membranas das sementes apresentaram danos ou estiverem em estágio de deterioração irão liberar solutos citoplasmáticos, estes dispõem de propriedade eletrolíticas, ou seja, possuem cargas elétricas (VIEIRA, 1994).

Para aferição de tais cargas utiliza-se o equipamento denominado condutivímetro que verifica a condutividade elétrica do material após o período de embebição, sendo este recomendado 24 horas a uma temperatura constante de $25^{\circ} \mathrm{C}$, a solução embregada no procedimento de embebição é água destilada (VIEIRA, 1994).

\section{TESTE DE TETRAZÓLIO}

O emprego de metodologias que possibilitem a obtenção de resultados a respeito da qualidade fisiológica das sementes de modo rápido e preciso, é imprescindível para tomadas de decisão de modo mais ágil sobre o destino dos lotes após os processos de colheita e beneficiamento, incluindo planejamento de comercialização e armazenamento (ISTA, 2008; BRASIL, 2009; TUNES et al., 2009).

O teste de tetrazólio se destaca dentre os testes rotineiramente empregos em laboratórios de análise de sementes pois possibilita seus resultados em um período de aproximadamente 24 horas. Fornece parâmetros a respeito de atributos não identificados nos demais teste descritos anteriormente, mais que afetam a qualidade fisiológica das sementes e dependendo de sua intensidade podem inviabilizar o lote, sendo eles danos mecânicos, ataque por insetos, danos gerados no processo de secagem e deterioração ocasionada por umidade (FRANÇA-NETO; KRZYZANOWSKI; COSTA, 1998; FRANÇA NETO, 1999). 
Propriedades do Teste de Tetrazólio

O teste de tetrazólio trata-se de uma solução incolor, difusível e se caracteriza pela reação química do sal de tetrazólio (2-3-5 trifenil cloreto de tetrazólio) com a atividade das enzimas desidrogenadas das células vivas, tais enzimas catalisam, ou seja, reduzem o sal de tetrazólio nos tecidos vivos. Nos locais onde ocorre este processo químico forma-se um composto de coloração avermelhada, sendo este, não difusível e estável (FRANÇA-NETO, 1999; CARVALHO et al., 2013).

Este composto de coloração vermelha denomina-se trifenilformazan, e sinalizam processo respiratório nas mitocôndrias, demonstrando desta maneira a viabilidade do tecido celular em questão. Tecidos não coloridos após o contato com o sal de tetrazólio são considerados inviáveis (mortos) em razão da ausência de atividade respiratória nas mitocôndrias (ELIAS et al., 2012, MARCOS FILHO, 2005).

\section{Metodologia para a Sementes de Feijão}

Devem ser submetidas ao teste pelo menos 100 sementes de cada amostra a ser avaliada, sendo estas subdivididas em duas repetições de 50 sementes cada; o primeiro procedimento a ser realizado é o pré-condicionamento das sementes que pode ser definido como a embebição das sementes em água (PIÑA-RODRIGUES; VALENTINI, 1995; ZUCARELI et al., 2001). Segundo Marcos Filho (2005) o procedimento de embebição das sementes além de resultar no amolecimento das mesmas facilitando deste modo o procedimento de corte, provoca também ativação do sistema enzimático, possibilitando a penetração da solução de tetrazólio e proporcionando uma coloração mais uniforme, com resultados mais seguros.

Em sementes de feijão o pré-condicionamento é conduzido entre folhas de papel umedecidas em água destilada (Figura 6), as sementes são colocadas intactas, ou seja, dispensam metodologias de preparo prévio, e são conservadas a uma temperatura constante de $25^{\circ} \mathrm{C}$, para isto Bhéring et al. (1996) sugeri que sejam mantidas no interior de um germinador regulado na devida temperatura por um período de 14 a 16 horas, entretanto este período pode chegar a 18 a 24 horas conforme descrito nas Regras para Análise de Sementes (BRASIL, 2009). 


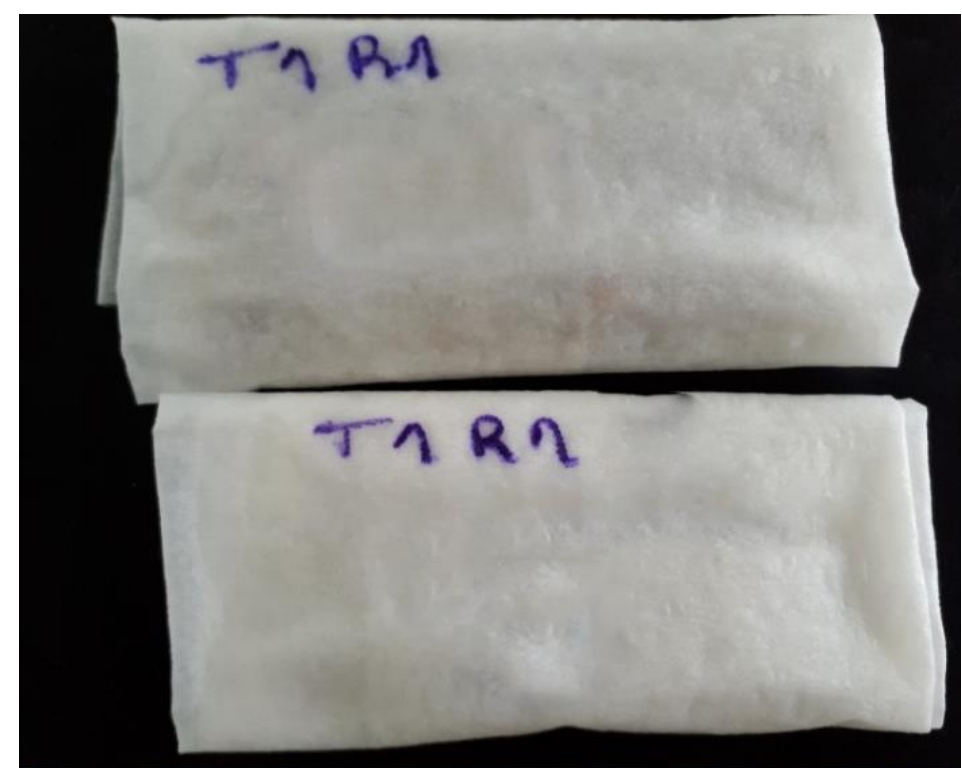

Figura 6 - Sementes de feijão entre folhas de papel umedecido para o procedimento de embebição (précondicionamento). Fonte: Tejo (2018).

Suprido o período de embebição as sementes são retiradas do contato com o papel umedecido e alojadas em béquer com capacidade de $80 \mathrm{ml}$, onde são imersas na solução de tetrazólio por um período que varia de 2 a 4 horas, sendo mantidas a uma temperatura constante de $40^{\circ} \mathrm{C}$, para isto a literatura recomenda o uso de estufas laboratoriais. Vale ressaltar que o volume de solução utilizado é apenas o suficiente para encobrir todas as sementes (BHÉRING et al., 1996; BRASIL, 2009).

A solução de tetrazólio pode ser empregada em diversas concentrações, entretanto para sementes de feijoeiro recomenda-se o uso das concentrações $0,075 \%$ ou $0,1 \%$, tais concentrações são preparadas a partir da solução estoque de 1,0\% (BHÉRING et al., 1996; BRASIL, 2009).

A solução estoque é preparada por meio da diluição de 10 gramas de sal de tetrazólio em $1000 \mathrm{ml}$ de água destilada, a concentração 0,1\% é preparada a partir da diluição de $100 \mathrm{ml}$ da solução estoque em $925 \mathrm{ml}$ de água destilada; já a concentração 0,075\% dilui-se $75 \mathrm{ml}$ da solução estoque em $900 \mathrm{ml}$ de água destilada, sempre deve-se respeitar esta proporção; o armazenamento das soluções deve ser realizado em vidros escuros de coloração âmbar ou envoltos com papel alumínio para evitar contato com a luminosidade (FRANÇA-NETO; KRZYZANOWSKI; COSTA, 1998).

Estudos conduzidos por França-Neto; Krzyzanowski; Costa, (1998) demonstraram que o ph da solução de tetrazólio não deve ser muito ácido pois comprometeriam o processo de coloração, logo os resultados proporcionados pelo teste também não transmitiriam segurança; o ph ideal deve ser entre 6 e 8, sendo raro as situações em que estarão abaixo de 4 ou até mesmo em 4. 
O processo de coloração deve ser realizado sobre ausência de luminosidade, visto que, trata-se de uma solução sensível a luz. Posteriormente ao período destinado a coloração, a solução é devidamente drenada do interior do béquer, e as sementes são submetidas ao procedimento da tríplice lavagem em água corrente, a fim de eliminar resíduos da solução nas sementes (BHÉRING et al., 1996).

A exposição das estruturas internas das sementes é realizada com intuito de possibilitar a avaliação das mesmas, para isso sugere-se que seja conduzido um seccionamento no sentido longitudinal entre os cotilédones das sementes, para tal procedimento aconselha-se o uso de uma pinça e bisturi laboratorial (Figura 7). Após o seccionamento, deve-se retirar o tegumento de ambos os cotilédones, sendo este comumente realizado de maneira manual e cuidadosa para evitar a concepção de novos danos nas estruturas a serem avaliadas (BRASIL, 2009).

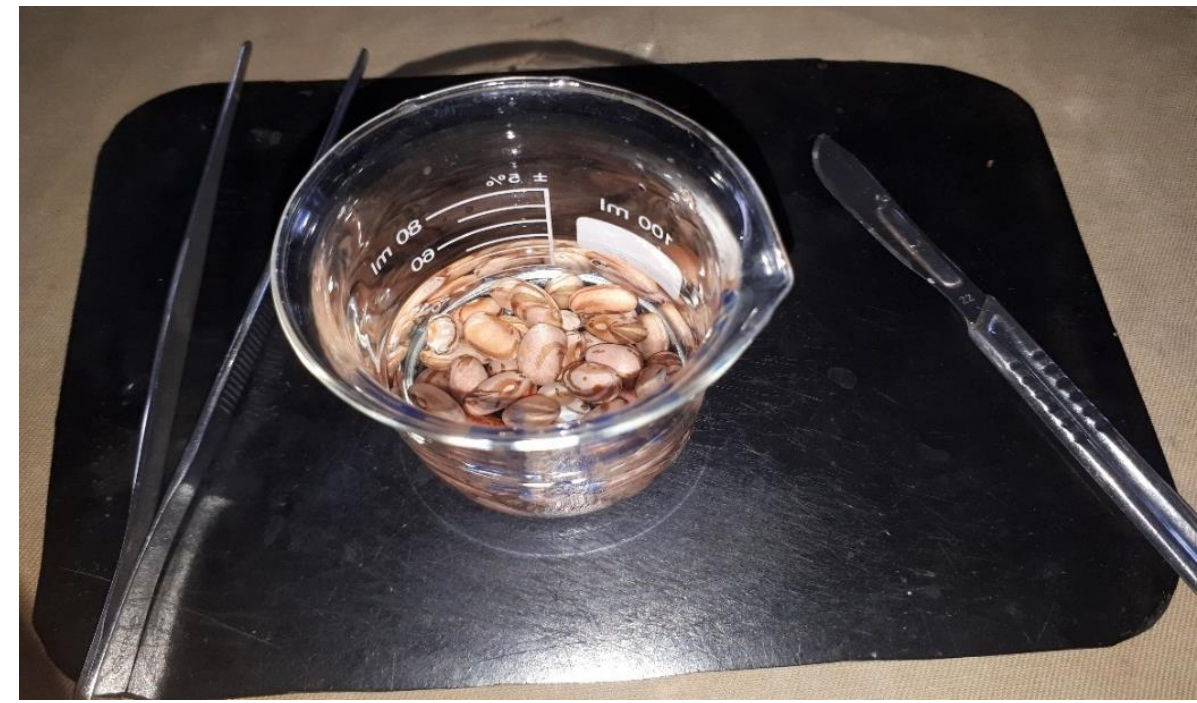

Figura 7 - Equipamentos utilizados para exposições das estruturas das sementes de feijão após a coloração das mesmas. Fonte: Tejo (2018).

\section{Avaliação do Teste de Tetrazólio em Sementes de Feijão}

As sementes devem ser avaliadas de modo individual, verificando as estruturas internas e externas, sendo que a estrutura interna abrange o eixo embrionário que por sua vez é constituído pela plúmula, eixo hipocótilo-radícula, córtex, cilindro central e radícula. Os danos identificados devem ser classificados como mecânicos, oriundos de ataques de insetos, ocasionados no processo de secagem ou por umidade (FRANÇA-NETO; KRZYZANOWSKI; COSTA, 1998; ELIAS et al., 2012).

Danos presentes na região embrionário (Figura 8), região superior das sementes, são considerados mais severos pois afetam diretamente o 
desenvolvimento da plântula normal em condições de campo, podendo resultar na formação de plântulas anormais, que dificilmente fechariam seu ciclo e proporcionariam boas produções, ou até mesmo causando morte do eixo embrionário, inviabilizando a semente. Esta etapa pode ser realizada com auxílio de lupas laboratoriais, com aumento de 6 vezes, priorizando equipamentos com iluminação do tipo fluorescente, requer também analistas bem capacitados aptos em relação as estruturas vitais das sementes (FRANÇA-NETO; KRZYZANOWSKI; COSTA, 1998; DIAS; BARROS, 1999).

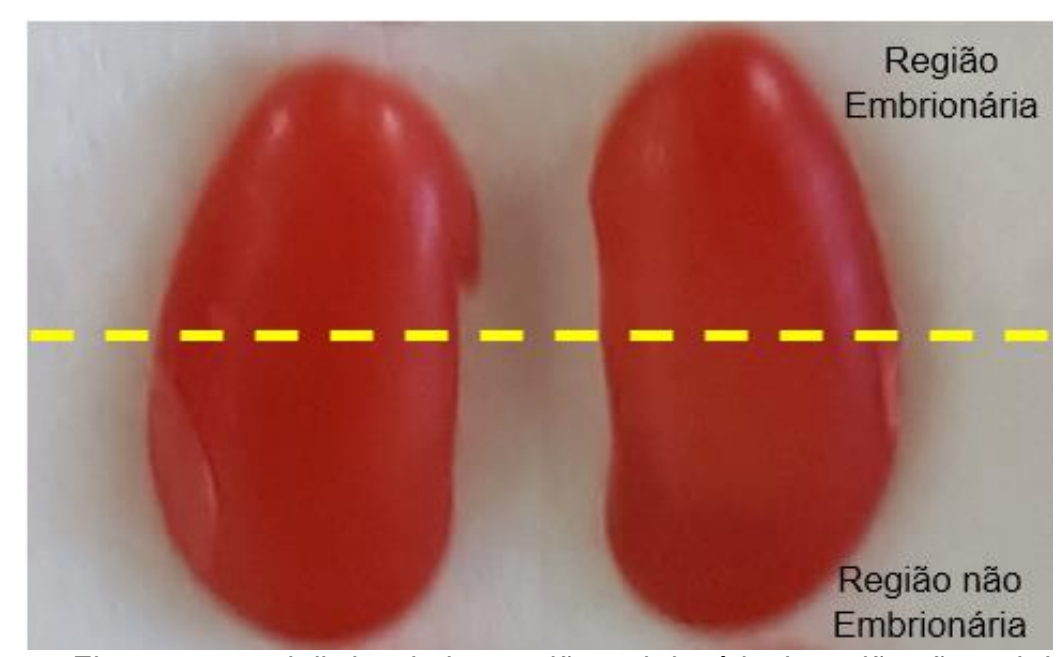

Figura 8 - Eixo transversal distinguindo a região embrionária da região não embrionária. Fonte: Tejo (2018).

A coloração ideal que as sementes de feijão comum devem exibir após contato com a solução de tetrazólio é vermelho-brilhante ou rosa-brilhante, indicando que o tecido está viável (vivo) e vigoroso; todavia as sementes podem se mostrar em tonalidade vermelho carmim forte indicando que o tecido está viável (vivo) porém não se trata de uma semente vigorosa pois está em estágio de deterioração; as sementes que após o período de coloração exibiram ausência de coloração, ou seja, estão brancas ou até mesmo amareladas com uma textura flácida, são consideradas mortas (tecido morto) (BHÉRING et al., 1996). Sendo assim o teste de tetrazólio fornece resultados seguros e de maneira rápida a respeito dos aspectos de viabilidade e vigor das sementes.

Bhéring et al. (1996) descreveu sete classes para avaliação e classificação das sementes de feijão submetidas ao teste de tetrazólio, sendo nas classes de 1 a 5 as sementes viáveis; na classe 6 inviaveis em razão de danos presentes em estruturas vitais como no eixo embrionário; e na classe 7 sementes mortas (Tabela 1). 
Tabela 1. Classes de avaliação do teste de tetrazólio para sementes de feijão comum.

\begin{tabular}{cc}
\hline Classe & Denominação \\
\hline 1 & Mais alto vigor \\
2 & Alto vigor \\
3 & Médio vigor \\
4 & Baixo vigor \\
5 & Mais baixo vigor \\
6 & Inviável \\
7 & Semente morta \\
\hline Fonte: Adaptado de Bhéring et al., (1996).
\end{tabular}

Nas classes de 1 a 3 encontra-se as sementes viáveis e vigorosas, a partir da classe 4 as sementes apresentam índices de vigor baixos, não sendo deste modo consideradas vigorosas (BHÉRING et al., 1996).

\section{CONCLUSÕES}

A qualidade fisiológica de sementes é rotineiramente determinada por meio de testes que verificam o desempenho das sementes em condições favoráveis (viabilidade) com o teste de germinação e em condições de estresse (vigor) por meio de metodologias como envelhecimento acelerado. O teste de tetrazólio se destaca por ser um teste que reuni resultados tanto a respeito da viabilidade como do vigor das amostras, um outro aspecto vantajoso de tal metodologia é sua agilidade na concepção de resultados de forma eficiente, além de permitir avaliação de outros parâmetros como danos mecânicos e de insetos. 


\section{REFERÊNCIAS}

ABDUL-BAKI, Aref Abdul; ANDERSON, James Donalt. Viability and leaching of sugars from germinating barley. Crop Science, Madison, v.10, n. 1, p. 31-34. 1970.

ASSOCIATION OF OFFICIAL SEED ANALYSTS - AOSA. The Association of Official Seed Analysts \& The Society of Commercial Seed Technologist. The Seed Technologist Newsletter, v. 83, n. 2. 2009.

BHÉRING, Maria Carmen, et al. Avaliação da viabilidade e do vigor de sementes de feijão de vagem (Phaseolus vulgaris L.) pelo teste de tetrazólio. Viçosa: UFV, 1996. 27 p.

BRASIL. Ministério da Agricultura e Reforma Agrária. Secretaria Nacional de Defesa Agropecuária. Departamento Nacional de Defesa Vegetal. Coordenação de Laboratório Vegetal. Regras para análise de sementes. Brasília, DF. 2009.

BRAZ, Madelon Rodrigues Sá; ROSSETTO, Claudia Antonia Vieira. Correlação entre testes para avaliação da qualidade de sementes de girassol e emergência das plântulas em campo. Ciência Rural, Santa Maria, v. 39, n. 7, p. 2004-2009, 2009.

CARVALHO, Nelson Moreira; NAKAGAWA, João. Sementes: ciência, tecnologia e produção. Vol. 4. Jaboticabal: Funep, 2000. 588p.

CARVALHO, Tereza Cristina, et al. Tetrazolium test adjustment for wheat seeds. Journal of Seed Science, v.35, p.361- 367, 2013.

DELOUCHE, James. Na accelerated aging techinique for predicting relative storability of crimson clover and tal fescue seed lots. Agronomy Abstracts, p. 40. 1965.

DELOUCHE, James. Qualidade e desempenho da semente. Revista Seed News, Pelotas, v.9, n.5, 2005.

DIAS, Maria Cristina Leme de Lima; BARROS, Alberto Sergio do Rego. Metodologia do teste de tetrazólio em sementes de milho. Vigor de sementes: conceitos e testes. Londrina: ABRATES, p. 1-10, 1999.

ELIAS, Sabry Gobran, et al. Seed testing: principles and pratices, Michigan, 2012.

FRANÇA NETO, José Barros. Vigor de sementes: conceitos e testes. Londrina: ABRATES. Cap 8.5, p.1-27, 1999.

FRANÇA NETO, José Barros; KRZYZANOWSKI, Francisco Carlos; COSTA, Nelson Pereira. O tetrazólio para sementes de soja. Embrapa-cnps, Londrina, p.72, 1998.

FRANÇA NETO, José Barros; KRZYZANOWSKI, Francisco Carlos; HENNING, Ademir Assis. Sementes de soja de alta qualidade: a base para altas produtividades. Quinto congreso de la soja del mercosur. 2011.

FRANCO, Daniel Fernandez; MAGALHAES JUNIOR, Adriano Martins de. Produção e avaliação da qualidade de sementes de arroz Irrigado. Pelotas: Embrapa Clima Temperado, 2011. 
INTERNATIONAL SEED TESTING ASSOCIATION - ISTA. Handbook of Vigour Test Methods. Zurich, Switzerland, ISTA, 1981. 72p.

KRZYZANOWSKI, Francisco Carlos. Semente não é custo e sim investimento. Informativo Abrates. vol.19, ํo.1, 2009.

KRZYZANOWSKI, Francisco Carlos; FRANCA NETO, José Barros. Vigor de Sementes. Seed News, Pelotas, n. 11, p. 20-21, 1999.

KRZYZANOWSKI, Francisco Carlos; FRANÇA-NETO, José Barros; HENNING, Ademir Assis. Relato dos testes de vigor disponíveis para as grandes culturas.Embrapa Soja-Artigo em periódico indexado (ALICE), 1991.

MARCOS FILHO, Júlio. Fisiologia de sementes de plantas cultivadas. Fealq, Piracicaba, p. 495, 2005.

MARCOS FILHO, Júlio. Teste de envelhecimento acelerado. In: VIEIRA, R.D.; CARVALHO, N.M. Testes de vigor em sementes. Jaboticabal: Funep, 1994.

MARCOS FILHO, Júlio. Testes de envelhecimento acelerado. In: KRZYZANOWSKI, F.C., VIEIRA, Roberval Dailton; FRANÇA NETO, José Barros. Vigor de sementes: conceitos e testes. Londrina: ABRATES, 1999. cap.3, p. 3-24.

MARCOS FILHO, Júlio; CICERO, Silvio Moure; SILVA, Walter Rodrigues. Teste de vigor. Piracicaba, 1987. 51p.

MARCOS FILHO, Júlio; NOVEMBRE, Ana Dionisia Coelho; CHAMMA, Helena Maria Carmignani Pescarin. Testes de envelhecimento acelerado e de deterioração controlada para avaliação do vigor de sementes de soja. Scientia Agricola, Piracicaba, v. 58, n. 2, 421-426, 2001.

NAKAGAWA, João. Metodologia do teste de tetrazólio em sementes de milho. In: KRZYZANOWSKI, F.C., VIEIRA, R.D., FRANÇA NETO, J.B. Vigor de sementes: conceitos e testes. Londrina: ABRATES, 1999. Cap. 2. p. 2-6.

NAKAGAWA, João. Testes de vigor baseados na avaliação das plântulas. In: VIEIRA, Roberval Daiton, CARVALHO, Nelson Moreira. (Ed.) Testes de vigor em sementes. Jaboticabal: FUNEP, 1994. p.49-85.

NONOGAKI, Hiroyuki; BASSEL, George; BEWLEY, Derek. Germination-Still a mystery. Plant Science. v.179, p. 574-581, 2010.

PERRY, David. Report of vigor test committee 1977-80. Seed Science and Technology, Zürich, v.9. n.1, p. 115-126. 1981.

PIÑA-RODRIGUES, Fatima Conceição Márquez; VALENTINI, Silvia Regia Toledo. Teste de tetrazólio. In: SILVA, A.; PIÑA-RODRIGES, F. C. M.; FIGLIOLIA, M. B. (Coord.). Manual de análise de sementes florestais. São Paulo: Instituto Florestal, 1995. p. 61 - 73. (Série Registros, 14).

POPINIGIS, Flavio. Fisiologia da semente. Agiplan, Brasília, p. 289, 1985.

TEKRONY, Dennis. Accelerated ageing test. In: VAN DE VENTER, H. A. Seed Vigour Testing Seminar. Copenhagen: ISTA, p.53-72. 1995. 
TUNES, Lilian Madrugada, et al. Tratamentos para superação da dormência em sementes de cevada. Scientia Agraria, v.10, n.1, p.15- 21, 2009.

VIEIRA, Edson Herculano Neves; RAVA, Carlos Agustin. Sementes de feijão. Embrapa Arroz e Feijão. Santo Antonio de Goiás, 2000.

VIEIRA, Roberval Daiton. Testes de condutividade elétrica. In: VIEIRA, R. D., CARVALHO, N. M. (Ed.) Testes de vigor em sementes. Jaboticabal: FUNEP, 1994. p. 103-132.

VIEIRA, Roberval Daiton; CARVALHO, Nelson Moreira. Testes de vigor em sementes. Jaboticabal: FUNEP, 1994. 164p.

ZUCARELI, Claudemir, et al. Preparação e coloração de sementes de farinha seca (Albizia hasslerii (Chodat) Bur.) para o teste de tetrazólio. Revista Brasileira de Sementes, Brasília, v. 23, n. 2, p. 186 - 191, 2001. 